\title{
FUTURE OF WORK: MANAGING EMPLOYEES EFFECTIVELY THROUGH THE COVID-19 CRISIS
}

\author{
Shoanna Dean \\ PGDM- HR Student \\ Welingkar Institute of Management, Mumbai
}

\begin{abstract}
The Covid-19 Crisis has forced the world's Organizations to reassess its priorities and shift to a virtual world, leading to a completely unexpected and earlier than planned paradigm shift. In order to survive in the Covid-19 world, they have had to make major organizational adaptations which will only be tested in time. What was earlier called as 'Future of Work' has in a matter of days become our present. These changes will have to be looked at from a long-term perspective as the chance of return to normal looks very bleak. The question now arises is what can organizations do to be future ready, for its employees and its business productivity. As we sail through the toughest waters, what makes or breaks the organization are its People and Leaders. Learning to put its employees first and making their experience integral to the organization's success is key during this crisis. The reality is we do not require managers managing the crisis but the need of the hour is leaders leading effectively through it. The approach of cultivating the service leader is very unique to the current crisis. It brings in the factor of Empathy which is so greatly diminishing as a trait among many leaders. As businesses begin to reopen in Asia and European countries, what organizations prioritize now more than ever before are the employees' health and safety. Standards of corporate hygiene will have to be high for the future in order to build resilience in the workforce.

In the study, the readers will get an overview of various new ways of managing employees that have emerged as a result of the Work from Home, the challenges organizations and employees face and how it affects productivity. One of the reassuring findings of the study is that Managers play a key role in ensuring employees deliver their best, which supports the importance of a leader in any team. Leaders are imperative to be there for employee support in a crisis. In times like these it becomes more important for managers to look at quality work rather than the quantity. They should start valuing a productive workday over a longer work day. Post the Covid-19 crisis, what organizations need is to rebuild a system and create what can be called 'real workers' and not just the 'ideal worker'.
\end{abstract}

Keywords- Covid-19, Productivity, Leadership, Work from Home, Corporate Hygiene, Talent Management.

\section{INTRODUCTION}

$31^{\text {st }}$ December 2019 will go down in history as the start of the biggest game changer for the world. At a time when the world was all set to welcome the New Year 2020, there was the origin of a pneumonia in China's Wuhan, Hubei Province with no cause identified. Later it came to be known as the novel Corona virus which today is referred to as the Covid-19 by the World Health Organization. This virus has not only devastated lives but also world economies, the super powers like the USA and emerging super powers such as India and shattered many hopes and dreams. It has put the Healthcare system in many countries under immense pressure to save lives and governments imposing lockdowns in order to flatten the curve and buy more time as scientists across the world scramble to develop a vaccine against the Covid-19. The virus has infected more than 16 million people across 200 countries and counting.

In an effort to reduce the tally and curb the spread, many countries had to take the route of a lockdown which had to be traded off with their economies being affected. It has forced countries to look at saving the lives of its people at the cost of a dwindling economy and a very bleak future laden with a recession which economists say could be much worse than the Great Depression of 1930s and Global Financial crisis of 2008. The Global Financial crisis of 2008 still send shivers down the spine of anyone who was impacted by it be it, either directly or indirectly. It was at the time, considered the worst hit to the financial industry and subsequently, the other industries too. The Covid-19 crisis today is almost comparable to it except for what caused these crises. One was due to a Financial fraud and the other is due to public- health crisis caused by a contagious virus. Both crises originated in one country but have had ripple effects in the entire world as a result of the globalized and connected world. Economic slowdown, Stock Prices falling, Job losses, Businesses going bankrupt. With the Covid-19 crisis, some of these impacts of the crisis will only show a positive upturn in a matter of time to tell.

While non-essential services have been completely stopped in the lockdown, it has also forced the world's Organizations to 
reassess its priorities and shift to a virtual world, leading to a completely unexpected and earlier than planned paradigm shift. For organizations, the implications are far too many. In order to survive in the Covid-19 world, they have had to make major organizational adaptations which will only be tested in time. Organizational resilience and employee agility will be key factors deciding the fate of the Organizations which will set the pace to eventually go past the survival mode and thrive in this new environment. While some industries have already successfully managed to reach the state of virtual sanctity with much ease due to the feasibility, the rest are still trying to rethink of how things can be done best for its organization and adapt effectively.

Interestingly, the new normal as they call it will be here to stay as the WHO recently announced that the Covid-19 virus could never go away and the world might have to live with it. This implies that the changes will have to be looked at from a longterm perspective. It can also be looked at as a blessing in disguise for some workplaces. This is a major turning point in history for workplaces to redesign the future of workspaces and a great opportunity to develop a resilient workforce by effectively managing their employees and emerging stronger than before, rather than a threat. This is the New Normal which organizations need to accept rather than fight to be at the top of their game. Employees are the greatest assets in times like these and it becomes imperative to take care of their needs and manage them effectively in order to build a greater and more powerful virtual workspace for all.

The Digital transformation of the workplace is inevitable as we make technological advancements in digital platforms, ecosystems, Models of operating supported by AI. In the same way that SARS accelerated the digital transformation in Asia with rise of Alibaba, Covid-19 has a similar effect on the global front.

As we sail through the toughest waters, what makes or breaks the organization are its People and Leaders. Without great leadership, it is impossible for the employees to put their best foot forward and without their employees, leaders will not be able to manage the tough times all alone. They are both codependent on each other in order to be stronger than ever before in a crisis. The new Work from Home is about technology being at the forefront, but it is also about a culture change. Organizations can look at this to revamp their culture and bring in sense of purpose driven culture. Learning to put its employees first and making their experience integral to the organization's success is key during this crisis.

In a crisis like this, employees become less motivated, have problems with trust and are unable to perform their duties owing to various factors and productivity inevitably gets affected thus slowing down the organizations path to recovery further. What can be done to manage employees in the Covid19 crisis? How can managers turn into great leaders to transform the way everyone looks at the crisis and how best to put your people first in a crisis? What are the most effective ways to keep people motivated through a crisis? What are the various concerns of employees and what can be done to address them?

\section{WORK FROM HOME: THE NEW NORMAL}

In a matter of few months, a massive growth in the number of coronavirus cases around the world has led to an exponential change across multiple functional ways of how we work. For millions of employees working with thousands of organizations be in the IT, Banking, Education and so on, their place of work and having a relaxed evening after that work have become one and the same. With the exception of a few industries such as healthcare, delivery services and those working as essential services, who do not have the option of taking their work home, they have had to take meticulous and sudden precautionary measures for safety and social distancing. In retrospect, it is clear now that this new Work from Home model that organizations have adopted will be here to stay for some time and they need to make the best of it for their employees. $90 \%$ of employers in a survey believe that is was essential and the more immediate requirement to give their employees the option of remote working.

There are several benefits of Work from Home for employees and employers. For employees they get to save on commute time and have a better work-life balance, while for employers, they get to save on their costs while getting better productivity and results. It is a silver lining they say, in the dark grey skies. The crisis makes us adopt an accelerated form of Smart work which involves remote work, reduced travel and virtual meetings and in the new now, it will be the standard which will be found across all organizations. It also gives rise to a flexible and more adaptive workforce. The crisis also makes organizations drive their digital readiness which eventually in the new now, will make themselves self-reliant on a robust digital backbone.

Since people are the assets of every organization, it is important that they look at their needs during the challenges that lie ahead. This can be done through the three deeply connected forces of an organization which are the work, the workforce and the workplace. For leaders, these are the biggest opportunities for them to lead the show as it is of utmost importance and how they rally their teams is the key.

A standard of smart work:

According to Strack et al (2020), accommodating virtual collaboration and remote work at scale: In order to maximize workforce productivity, these are practices that must be efficiently handled and sustainable. Identifying best practices, establishing new forms of leadership presence, getting employees feedback and creating virtual social intimacy are some of the ways.

Setting up smart work spaces: Incorporating technology that collaborates with the personal and human touch helps support greater social and team building. It should be done at offices, at home offices and at the production facilities. 
Cost upside: This method surely shows that there is a saving of cost which was earlier spent on huge office spaces. With the adoption of new policies to support smart work at home, it will help usher in a more sophisticated and digitized way of work across the organization.

\section{The Elastic Digital workplace:}

The crisis has fast forwarded the digital readiness of the world 5 to 10 years into the future and has given organizations the opportunity to change and accelerate the digital revolution to simplify their operating models.

Prioritizing employees who have critical roles in the organization by ensuring they have access to all the tools to begin with. Also important is to implement virtual desktop solutions which enable employees to have secure access to remote applications.

By harnessing data and digital platforms, human and technological collaboration can help bring out and reinforce the most trusted and efficient, a flexible and adaptive data driven and digital organization. Here, companies can use data and analytics to give their employees better tools for decision making and support functions. Organizations can start adopting a digital work culture on a large scale and help their employees to work remotely through digital collaboration tools.

\section{Adopting agile at scale}

Organizations will have to incorporate and adapt to large ecosystem of roles and tasks in order to survive the crisis. Every other aspect of Employee Management such as Performance, Learning and Development, employee career path will also evolve and change alongside employer value proposition. The skills and employees who thrive in the new environment will be the ones who will emerge successful and promoted. It is absolutely necessary for everyone to thrive in an environment to reach the goal. Simplifying and shortening processes and models, decreasing administration and nonvalue-added tasks will build resilience. Redeploying teams to core activities will be another factor to look at.

Evaluating what work the organization is required to perform and prioritizing is key. Ensure that teams focus on the more important tasks and empowering them to be more creative in delivering non-essential tasks will give them a sense of autonomy.

Working productively from any remote location requires seamless and secure internet connectivity which is a prerequisite of a Work from Home setup. Employees need to connect to partners, their team members, cloud systems and corporate networks. It is also a great idea to implement interactive sessions and web conferences for greater exchange of knowledge and ideas. Webinars are being used by various organizations to bring together the best minds to deliver and ponder on issues of the work places. All this can be enabled with a good IT interface.
Another aspect organizations have to consider is the psychological impact on its employees. They have started virtual yoga counselling sessions for their employees, thus seeing a more holistic approach to both mental and physical wellness is become the need of the hour.

\section{The challenge of Work from Home}

While some of the employees see the Work from Home culture as a welcome change in their lives, it is also dreaded news for a lot of them. These include those who have families and kids who can be a constant source of distraction and therefore, concentration, mental peace, productivity and creativity gets affected. These challenges and opportunities are now looked at more profoundly than ever before as the change has forced everyone to experience it firsthand. Instead of being ignorant towards it, they are now starting to work out a way around it. The main issue here is the blurring of boundaries between home and Work from Home, which as a matter of fact is difficult unless the person is always locked inside a room. Companies are working on creating deeper insights as to the challenges faced through surveys which uncover a variety of circumstances and stressors for the employees. It is different for a single person living and working from home as opposed to a working member of a family with children and parents. The issue of exhaustion and focusing during work hours get troublesome for the latter. It becomes important for leadership to consider all such situations and signal that unorthodox working hours is alright and there should be more flexibility given to them. Cocreating new schedule for employees is a great way to go in the direction. Executives from one organization were given the option to identify blocks of timing when they would be 'on' and when they would be 'off'. The schedules are then shared and the teams are aware as to the pattern of their communication and availability and when to expect timely responses from these employees. Having a one-size-fits-all approach will not work in the case of virtual workspaces as everyone is not on a level playing field here. Organizations can create collaborative platform where the employees who face similar challenges at home can come together at regular or once a week meeting to share their ideas, guide and mentor each other and share interesting experiments. For the organization, the platform is a great way to share and channel specific needs and ideas with the management as well. This will enable the management to bring in and think of helping their employees, being more empathetic and caring towards their concerns.

\section{LEADERS LEAD THE WAY OUT OF THE TUNNEL}

Putting people first is crucial in times of a crisis and it is time for leaders to lead for the safety and welfare of their employees. How they lead will leave a legacy for the future generations and over the long term and good deeds will be remembered perennially. According to Mazanek (2015), it is 
the Leaders duty and responsibility to give its followers hope and faith in the workplace

The reality is we do not require managers managing the crisis but the need of the hour is leaders leading effectively through it. The key difference between leaders and managers that the former has evolved over dealing with budgets and plans to formulating strategies and vision. Leaders need to be active members of the organization to lead the people through the crisis, not just manage the crisis and the people. In order for that, leaders need to walk beside the people to lead them. Priorities need to be reflected in the Leader's optimism and communication. They need to show the way of hope and faith in the crisis. Leaders also lead the way by being in control and not being afraid to show it. They take responsibility for their actions and decisions. In the time of crises like these, the true caliber of the leader is tested and the leaders who reassure their people, drive the connections, make them adapt and adapt themselves to the changing environment will be the ones who will see the light at the end of the tunnel. Leaders must shape the 'New Normal' instead of just letting it emerge.

In a crisis, the leaders absorb in large amounts of complex information, emotions and contradicting opinions on a regular basis. They need to be aware of the outside world, not just limiting themselves to the organization they work in and its bubble and the inside world which is their body and mind. 'Interoception' and 'Exteroception' which are common terms used in neuroscience are applicable to crisis management at its core. It is referred to as integrative awareness, where one needs to be in tune with the situational awareness as well as inner awareness. This enables leaders to stop jumping to conclusions and over reacting to situations brought to their notice, instead they develop the quality to pause and reflect before they make a reaction and eventual decision. Leaders roles in creating meaning of every situation grows steadily and steeply in a crisis. They are forever visible, even in the virtual world as their authentic role model behavior for the organization is important. Distress a is common sign of being affected by the crisis in employees and they need to connect and engage in positive ways with outside people to remain healthy, both mentally and physically. This is where the leader's vision on dealing with a crisis is very meaningful and they expect to be connected at a personal level too. In these cases, video "townhalls" provide the best platform for engagement between the leaders of an organization and find out what are the concerns facing their employees and what they feel about the situation.

To cite an example, when Captain Sullenberger of the famous Hudson river water landing(ditching) in 2009 where he demonstrated the so-called integrative awareness. He stayed calm when birds hit the aircraft engine and thrust was lost in both engines, forcing him to deliberate whether to return to an airport or to land in the Hudson river. He managed to stay calm, even though the situation was fearful as he had the lives of 158 people in his hands. The balancing of his internal emotional state and the external situation of what he thought was best for everyone is what is called metacognition.

There are 4 leadership traits which can help leaders shepherd their employees out of the crisis: Awareness, which is profoundly spoken of in the previous paragraphs. Second, exhibiting vulnerability by lowering their guard and being at the same level as the employees to connect with them. Third, empathizing to show employees they can feel what they feel demonstrating it to them ensuring the feel genuinely cared for, which brings us to the fourth, compassion.

Employees in crisis need to feel heard and included. They feel the need to express themselves freely and without being judged and leaders needs to welcome more diversified expressions of feeling. Trust, inclusivity, sense of belonging with the rest of the team helped to reduce personal stress levels and increases commitment in employees. It is important that leaders express gratitude for the work their employees do even in the crisis, against all odds and should never miss an opportunity to appreciate their employees through organization-wide thank-a-thons and should encourage others in their organization to do the same, to bring in a mutually supportive work culture.

\section{Leading with empathy and direction}

A crisis triggers many psychological and physiological responses that include distress and heightened sensitivity, traumas resurface and the lost sense of security and normalcy can add to the grief, with it come feelings such as shock, denial, anger and depression. Under these Circumstances, it becomes very important for leaders to demonstrate visibly caring leadership. Awareness, Compassion, Vulnerability and Empathy are 4 traits for leaders to show they care for their employees in a crisis and set the stage for a turnaround business recovery as mentioned in the work of Neilson et al. (2020)

With a solid $3 \mathrm{H}$ mindset, the head, heart and hands, every manager is capable of turning into a leader. The head envisions the future, the heart inspires the employees and empowers them, the hands to execute agile and innovative capabilities. Before the Covid-19 crisis, the heart was completely ignored while managing employees. This new element of leading can do wonders for organizations and employees to gain trust and hope in their future. In the virtual environment, where work and people seem distant, it become the responsibility of the leader to maintain frequent and exclusive checks with their employees to show solidarity. These include weekly pulse tools, digital focus groups, a continuous feedback culture which will help the leaders source data from their immediate subordinates and give them a listening ear so that they feel included and cared for. There is tremendous stress on the need for leader's empathy which will become a hallmark in every organization very soon. It will be tested before leaders are promoted to leadership roles in the future. 
Front-line leaders

People, when they think of a leader think of the C-suite position holders but the real leaders are the ones who interact daily with the employees and take care of their needs, who directly supervise the line employees. These Managers have a direct influence on the work of the employees and must therefore be given due respect for their work. The frontline leaders are responsible for major organizational changes and can make or break the adaptation of an organization who is transforming its workplace to virtual, which is practically majority of the organizations. It is imperative that these leaders are trained well to deal with the employees and their daily work concerns. They are the ones to directly impact Diversity and Inclusion initiatives which are crucial while storming through a crisis. When employees feel heard and included in decision making, they are more likely to be committed and work more productively. Also, these leaders need to manage agile teams and entails that they give them direction, provide autonomy and focus more on the results rather than the process. Organizations need to put in the requisite effort to increase the support provided to the frontline manager, in the new virtual workspaces.

\section{The Transformational Leadership theory and its application}

A Transformational leader is someone whose leadership style is most critical in a crisis which is defined in the work of Sermenis et al. (2019). Developed in 1978, the theory determines the relationship between the leader and its followers and their behavior in a crisis. The 2 parties commit to each psychologically in the long run, and the leader changes the beliefs, values and needs of the followers and the two collaborate together to achieve their vision. There is a social exchange in the process. Transformational leaders show care for their followers and empower them to achieve goals. The leader gives them inspirational motivation, intellectual stimulation and individual consideration and idealized influence which are the 4 characteristics of the transformational leader. This leadership style is perfect for any leader in the Covid-19 crisis to adopt for their organization and its employees. Through idealized influence, they inculcate shared values and vision with the employees which is to sustain the organization through the crisis. The leader commits to high standards and sets himself as a role model for the employees to follow, Employees can thus associate themselves with the leader and follow their beliefs and values as their own. With individual consideration, the leader recognizes that every individual needs and desires are cared for such as the new needs in the Work from Home environment or other health requirements in the Covid-19 crisis. Intellectual stimulation means that the leader motivates the employees to come up with innovative solutions to the problem, and also helps them and involves them in the decision-making process. Knowledge sharing and innovation/creative ideas are encouraged to a great extent. Inspirational motivation is where the leader collaborates with the employees by taking their interests, opinions and demands into consideration to reach the organizational goals. Employees need to see culture expressed in meaningful ways and leaders acting as role-models of the values is one of them according to Berman et al. (2020)

\section{The Service-Leadership approach}

The approach of cultivating the service leader is very unique to the current crisis. It brings in the factor of Empathy which is so greatly diminishing as a trait among many leaders. Power as research suggests reduces the empathy from the brain and leader begin to treat people as objects. It is an era where it common to treat people like numbers and dehumanize them. Hence it becomes all the more important to for leaders to be empathetic and most importantly humble and act in service of others, in order to empower them to do their best in the crisis. The leaders and organizations that put their employees and the human values at the core will imminently get their people into the thriving mode.

\section{EMPLOYEE SAFETY AND HEALTH MATTERS}

As businesses begin to reopen in many countries, what organizations prioritize now more than ever before are the employees' health and safety. HR needs to make it clear to their employees that no one can be forced to come back to work if they are not comfortable to. When the lockdown gets lifted and economies begin to open, organizations need to prepare for that day to come ad revamp their entire office building. Although few industries are capable of continuing with the Work from Home model, not all industries and the organizations can implement it. Most affected are the industries of travel and tourism and healthcare and the retail sector where customer face-to-face interaction is the most important part of the business. It therefore becomes necessary for these organizations to come up with strategies for an easier and smoother return for its employees. Let's look at some lesson from the Asian countries.

The experience these countries have suggest transparency, flexibility and iteration are key to the plans of returning to the workplace. The basic requirements for any office is in-facility safeguards such as face masks, sanitizer, temperature screenings, social distancing norms and a regular and aggressive cleaning schedule of every part of the building and the office facility where employees could be exposed. Reducing "hot desking" is the first and foremost for meeting rooms, cafeteria and work areas and organizations need to look at revamping their floor plans in order to drive social distancing strictly. Transportation needs to be looked at more closely for employees who travel by public transport by either giving them a transport allowance or providing them with a shuttle bus while maintaining social distancing in the bus. Most organizations that have brought back their employees have done it in phases and in a staggered way so as to reduce the sudden pressure on the basis of the nature of the work of employees. They can also use workforce analysis and draw 
insights to see who can return and when. It is important that employees who are asked to return feel confident and hence the HR should ask only those employees to return who health is not at risk. It is best for those who travelled on site for client meeting and projects to now stay put until the virus is completely out. At this juncture, virtual meeting and Work from Home are the best strategies to keep the employees safe and healthy.

It is important to note that there is nothing such as zero risk and there are chances of Covid-19 never going away as mentioned by WHO. According to Allen et al (2020), the goal of most organizations is to minimize the risk factors and the organizations can reach that by following a layered defense approach by applying the hierarchy of controls. This hierarchy can now be followed by all organizations irrespective of industry one is working in.

\section{Minimizing Risk in the Workplace} Using a hierarchy of controls as a response framework,
companies can take a range of actions - weighing
the effectiveness and financial impact of each - to
combat Covid-19 in their buildings.

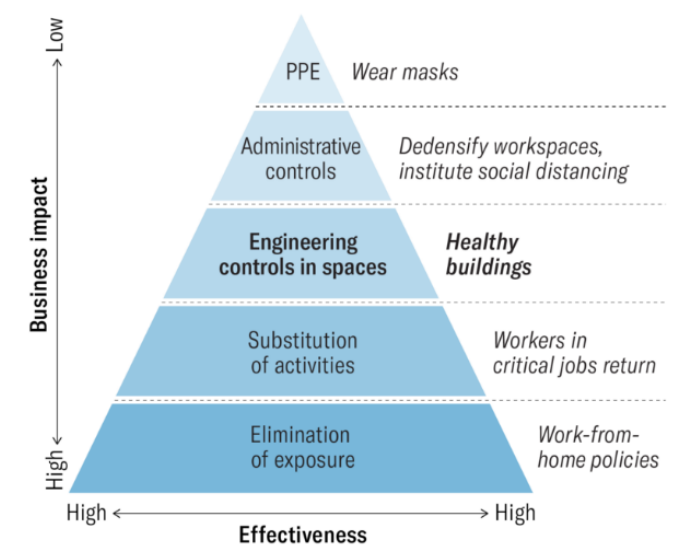

Note: "PPE" stands for personal protective equipment Source: Joseph Allen and John Macomber

Source: Harvard Business Review

In addition to the framework above, "unused space" as a result of layoffs and Work from Home models can be repurposed for health and rejuvenation purposes. Common areas should be used in order to spread out work forces. Meetings which need more than 10 employees should be continued on virtual platforms.

Measuring the success of these initiatives can be done through what is called a Health Performance Indicator (HPIs). Healthy individuals also perform better. These indicators can be used to assess the air quality and pulse of the building.

\section{Health Performance Indicators}

HPIs can be divided into four quadrants according to the timing of indicators and what they measure.

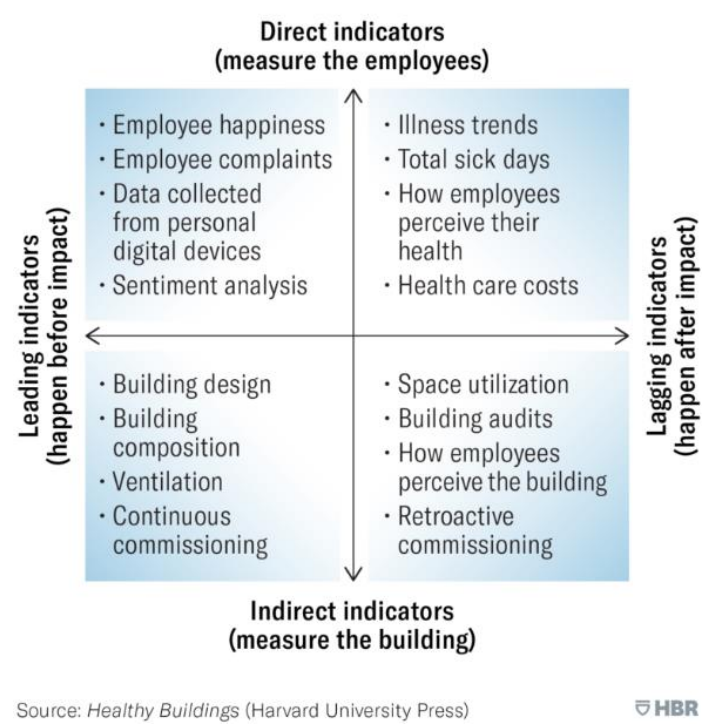

Source: Harvard Business Review.

The top half of the grid indicates what are the things an organization needs to evaluate in its employees and the bottom half represents what factors it must evaluate in its office building. These efforts which seem costly at first will reap benefits for the future to stall any more pandemics that could be in store. This will also ensure future talent will be more eager and open to join the organizations and while interviewers are interviewing them to see how fit they are to join; interviewees are going to interview the building. Thus, standard of corporate hygiene will have to be high for the future in order to build resilience in the workforce

\section{TALENT MANAGEMENT AND EMPLOYEE PRODUCTIVITY}

With business continuity being one of key focuses for organizations in the Covid-19 crisis, the spotlight then shifts on various talent management facets. Talent acquisition being one of them, organizations need to looks at newer ways to manage its workforce such as redeployment of talent, job rotations, gig workforce to name a few in order to maintain workforce agility and transitions. Creating an adaptive learning system is one of the biggest work force and corporate lessons in this crisis. As part of their daily regimes, both leaders as well as the employees need to learn new skills, acquire knowledge and be more updated with the changing times. Soon the norm will be to have a learning aspect in every single meeting, peer learning and coaching, frequent rotations across roles and functions 
In order to upskill and reskill by building a strong digital capability for the organizations at scale, they need to use AI and Big Data to design and customize upskilling for its employees, with the perfect mix of various platforms be it virtual sessions, on the job training and practicing, in addition to having various micro nudges and learning and development boosts for employees. One such example of the new ways of bringing in employee capabilities at scale is the BOT Model (Build-Operate-Transfer) which is being used by organizations. In such programs, internal digital skills are built as new talent works alongside experts in the field who then coach and mentor these programs themselves while also delivering digital priorities.

The dominance of new AI based technology to hire and manage talent will be used more proactively and frequently. It makes it possible for organizations to assess and analyze individual skill levels and address upskilling requirement. They can also help decide whether one should hire gig workers, contractors or having flexible hours. This has also brought in the shift of talent requirement from over-capacity full areas to areas which are scarce in the organizations and thus brings in the broader skill set requirement.

Working models have to be revamped according to the organizations main purpose. This will be based on 3 factors to help organizations decide what model to adopt and tailor the work model adapting to the changes.

- Space, which tells you how much work can be done on site and how much work can be done remotely.

- Time, being a major factor here, where in organizations will analyze how work time can be made flexible or reduced

- Form of affiliation with the organization, which means how is the employee hired, if contract base, contingent, full-time, gig, freelance and so on.

Organization must even think of setting up 'gig squads.' This is a great way to have the best talent in your organization who are highly skilled and can be retained for a set number of working hours. There is an exchange of expertise and knowledge, while the squad work with full flexibility.

Based on the flexible working models, there will also be a requirement to change the KPIs and performance metrics. There were many drawbacks of the current rigid and fixed system of working, which has the crisis has taught organizations to look at a flexible remuneration and compensation system which will definitely mean looking at it with increased nuanced considerations. Organizations need to realize sooner, the need to future proof their workforce, by reskilling and upskilling their employees. In a survey conducted by BCG, $67 \%$ of the respondent are willing and are eager to learn in any situation and $29 \%$ would reskill if they hit a roadblock in their career. Organizations should see this as an opportunity to foster and promote lifelong learning in order to stay ahead of the game and weather the storm which has been brought by the current crisis.
With the Work-from-Home and remote models of working coming to the forefront in many organizations, there could be a possibility and chance to improve workforce diversity and inclusion. This has proven to be both economically beneficial as well as bring in a competitive advantage for the organization. It helps reduce turnover, retain their most talented employees and bring in innovation. More women with families can become part of the workforce with Work from Home in effect. Diversity is not only gender but also ethnicity, age, nationality, sexual orientation, physical condition, language and beliefs. Teams working remotely are noted to have decreased productivity due to decreased motivation levels. In order to bring in more engagement for teams, their work needs to be more engaging. Take a look at the graphics below

\section{Employees Who Work Remotely Are Less Motivated}

In measuring motivation, employees who worked remotely were less motivated, and those who had no choice about it were the least motivated of all.

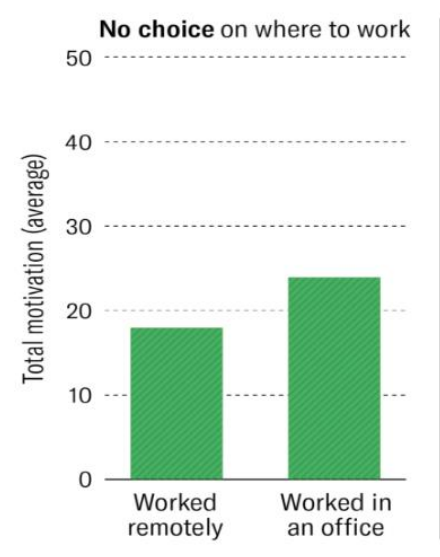

Choice on where to work

Note: Total motivation is based on a survey of 9,700 U.S. workers. Respondents were asked six questions about their motives for work; their answers were assigned a value using a 1-7 scale. The results were synthesized on a scale of -100 to +100 points. Motive are weighted according to the impact they have on performance. Source: Primed to Perform, by Lindsay McGregor and Neel Doshi

Source: Harvard Business Review 


\section{Employees Who Are Empowered to Experiment Are More Motivated}

Giving workers the freedom to experiment and solve meaningful problems in their roles leads to higher motivation, regardless of where they do the work itself.

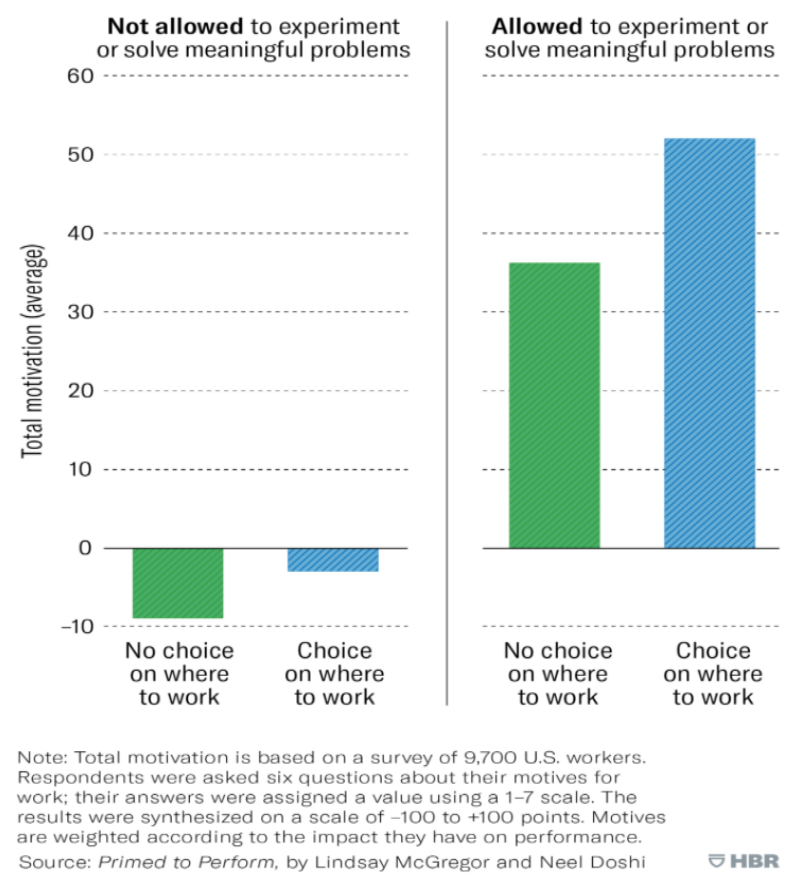

Source: Harvard Business Review.

These Graphs show that the work place is not really a matter of concern for employees to perform but it's the kind of work they are doing that motivates them to be more productive. Also, if employees are given a choice of where to work, their motivation increases.

\section{ORGANIZATIONAL CULTURE AND DESIGN}

Researchers Gibson et al. (2000) define organizational culture as what employees perceive and how this perception creates a sum of values, expectation and beliefs. Crisis Leadership begins with setting an adaptive organizational culture which is not too rigid and sailing through a crisis through change is easier. Aligning purpose, vision and values will help organizations drive and motivate employees better. Having a purpose-driven culture is important as it a deep reflection of the organization corporate identity. It is deeply interconnected to the people who are part of that organization. Connecting this purpose to the heart of the organization means reappraising and reigniting your core values which also includes your strategy, operations and the organization itself. At this point, it also becomes important to link the employees' purpose with the organizations purpose. This will definitely help increase employees' performance and productivity. Organizations should create a culture of resilience and encourage its employees as well as leaders to reflect from the learnings and continue moving forward. This can be done by learning from experiments with new technology, working across silos and forming new routines with the changes at work. This successful adoption of culture change will help organizations create and move along the success momentum they create.

According to Strack et al. (2009), a crucial test of the Organizational Culture of a company is how its employees are treated in a crisis since, when good times return, employees will have it etched in their minds, how the organization treated them. Organizational design too plays a key role in keeping up with the pace of the changes happening across the work place and organizations can seek ways to change their designs to fit into the current trends to be remain agile. Design directly corresponds with employee experience which is what HR needs to look at in the current crisis. How can they make the life of their employees more hassle free and give them the benefits they are looking for? With the new normal it becomes all the more imperative to retain top talent as they will be the future of the organization when the tide has fallen. Giving them the best employee experience will make them more motivated and loyal to their organizations.

\section{MAJOR FINDINGS OF THE STUDY}

As part of the study, data was collected both through Primary and Secondary research. Primary research involves a survey conducted. Judgement or purposive Sampling technique was used as the study was based on working professionals and especially those whose organizations have Work from Home policy in effect during the Covid-19 crisis. A total of 120 plus respondents participated in the survey covering various questions based on how leadership, Work from Home, keeping in mind the challenges they face and what are the key factors that make or break the new normal, and how effective it is.

An analysis of the primary research has given rise to the following major findings:

1. According to most respondents, Work from Home can be implemented by their organizations even post Covid-19, irrespective of the industry. This is good to know since, there are many benefits of the Work from Home model for both employees as well as organizations which can be reaped if there is proper execution of the model

2. The impact of Covid-19 on work is felt across almost $42 \%$ respondents of all industries negatively while $37 \%$ say there is no negative impact on their work. Here we talk about individual work. Within industries, which for example the banking, education and IT, there is again not much difference in the number of employees whose work is impacted and whose work is not and hence, one can say safely say that all industries have an equal proportion of both. It does not depend on the industry but the kind of work/role of the employee.

3. When asked to rate their productivity at home and at the office, productivity was rated higher at the office compared to home for $51.60 \%$ respondents, while $24 \%$ felt it was higher at 
home and the rest (22\%) felt no difference. This came as a bit of shock considering that most people would have thought that employees would be more productive at home. Although the difference is not startling, there is still a slight one and it could be attributed to factors such as more distractions at home, no fixed hours of work and ability to work at one's own pace. Productivity could also be decreasing where teams needs to collaborate with each other to bring out creativity and knowledge sharing among the peers.

4. $50 \%$ of the respondents believe that they have been able to restore work-life balance with Work from Home. This is a given. Considering that most employees save time on commuting and are able to spend their free time to focus on things apart from their work.

5. Managers/ supervisors play a key role in ensuring employees deliver their best according to $84 \%$ respondents. It is one the most reassuring findings of the study, which supports the importance of a leader in any team. Leaders are imperative to be there for employee support in a crisis

6. $78 \%$ respondents believe they have the necessary support from their organizations to manage Work from Home. Thus, it is established that organizations have been providing their employees with the IT support which is crucial for Work from Home to be successful

7. $79 \%$ respondents believe that they want to upskill themselves during the crisis and be abreast with the changing times and that their organizations must help them do so. Although it is not the most immediate priority on employees' minds right now, it is still an important aspect for their growth as they see the Covid-19 crisis as a trigger and virtual world to upskill themselves. What better way to utilize one's free time! $8.79 \%$ of the respondents believe that doing meaningful work was key to being motivated, irrespective of the work place (office or home) which further reinforces the results of a study conducted by Harvard. This is important for organizations to note as they redesign their work models, while looking at new digital ways of setting up their workplaces.

9. Contracting the virus $(40 \%)$ and job security (32\%) were the biggest concerns for most of the respondents, while only $7 \%$ each had concerns about finding a new job and getting a promotion, thus indicating a shift in priority for employees in the crisis. This makes it important for organizations to put employee's health and safety first and taking all necessary precaution is the ultimate way to making them less apprehensive when they might have to get back to the office.

10. Majority respondents believe that $(51 \%)$ they are putting in more hours into work at home than at the office. This could be linked to the fact that respondents also believe that they have been seeing fall in their productivity, owing to fact that they have been putting in more hours into work than at the office. They link the time they put into work and productivity. Higher number of hours being put into something doesn't necessarily mean one is being productive.

11. Priorities such family and personal health $\left(1^{\text {st }}\right)$ and job $\operatorname{security}\left(2^{\text {nd }}\right)$ were rated higher for most respondents. Having a supportive manager came in $3^{\text {rd }}$. While developing hobbies and salary were of least priority for the respondents. These are all in line with our other findings also.

12. The most common reasons for employees to like working from home the Work-life balance, time saved due to no travel, flexibility, higher productivity, time for self and family, working in casuals. These are factors that are primarily reasons for employees to decide whether they like going to office or not and can be used to the organizations advantage in determining future workplace strategies and models.

13. Common things that employees do not like about Work from Home are no fixed work hours, blurring of work-life balance, lower productivity, distractions, less social interaction with peers and less human connect, excessive virtual meetings, ineffective communication, work and home getting blended too much and expectation to be available on weekends. It can be inferred that employees prefer face to face interaction with peers rather than virtual meetings.

14. Some employees said they like the flexibility they get from working at home and some said that no fixed hours were a problem. Thus, it also depends on the perspective of the employees and how they look at it.

15. While some seen their productivity being higher in case of Work from Home, as they don't have to spend time in commuting daily and get more work done subsequently and also because they get to do their work at their own pace. Others find their productivity being lower as they end up being lazy at home and have more distractions due to family being around.

16. Most people said they have been able to achieve work-life balance due to the time on hand, few others believe that their work-life balance is not there as there is no boundary between work and home. Employees are expected to be available anytime and that causes more work hours.

17. Some respondents said that they have more flexibility while some said that having more flexibility meant no fixed work hours.

18. Thus, we see how employees see certain aspects of the same thing in two very different ways giving rise to varied perceptions on how to manage ones work at home. This brings in the role of a Manager who can try to bridge the gap for employees' expectations and organization's expectations

\section{RECOMMENDATIONS}

\section{Blended Workplace Model.}

The Work from Home model may not be the best one for an organization, and must not be used to completely overthrow the physical workplace but to complement it. It means trying a new approach altogether which is having the best of both worlds for its employees. Organizations need to understand and factor in, the needs of its employees, their employee experience, their expectations, while also prioritizing their health and safety. Work from Home is established as a great way to save a lot of time, effort and costs for all. Most 
organizations are recognizing that they could use it post Covid-19 as it permits them to do so. However, it may not be the most full-proof way to resolve the post Covid-19 effects that is glaring ahead in the future. Hence, it is recommended that organization bring in a blend of the two: An Office culture supported by the Work from Home culture. It will not only help organization address the health concerns of the employees but also help in maintaining the social distancing norms which are here to stay. Employees whose role permit them to take their work home, can adopt this style of working if it benefits them. Organizations can even give their employees the freedom to decide or could have a 50-50 approach where teams can rotate and work from Home and Office both during a month. This way it gives employees flexibility and takes away monotony in their work life, bring in the feeling of socializing with their peers and makes them more productive. It is important to note that not every employee has the best internet connectivity or the ideal workstation. Hence, it is critical that organizations value their employees by checking on their individual needs and requirements. This is all part of the employee experience. If an employee feels taken care of, there is automatically a change in his outlook towards work. Organizations can even support the employees by providing them with a workstation at home with the necessary IT support. Also, teams which require collaboration of minds, creative and knowledge sharing which can be best brought out through face to face human interactions would benefit from the office workspace.

\section{Direct Approach Manager}

Reinforcing the decentralized organizational structure, this approach allows organizations to be more employee centric. The way this works is by having a direct manager for every employee (1:4 or 1:5) which will help in personalized employee development. This will help in increasing productivity and issues faced by employees get direct and undivided attention. When employees feel heard and important, it gives boosts their feelings of loyalty and commitment to the organization. In larger organizations it is recommended to have $1: 8$ to $1: 10$. The manager can therefore be a true leader in the crisis and show the service leadership approach to managing their employees. Since leaders are the backbone of any organization, having a personalized leader for employees fosters greater engagement and peer to peer learning. These ways are shown to drive employee performance in the organization.

\section{Recommended Model for organizations.}

\section{Reassess}

While organizations are gathering their data, they should assess their employee requirements and workforce requirement, in accordance with the new now. It is important for organizations to be extremely mindful while assessing where and how to secure employees jobs, as many organizations will want to layoff. Rather look at the long-term perspective to see where the organization is headed post Covid-19. They also need to reassess their priorities put employee health first.

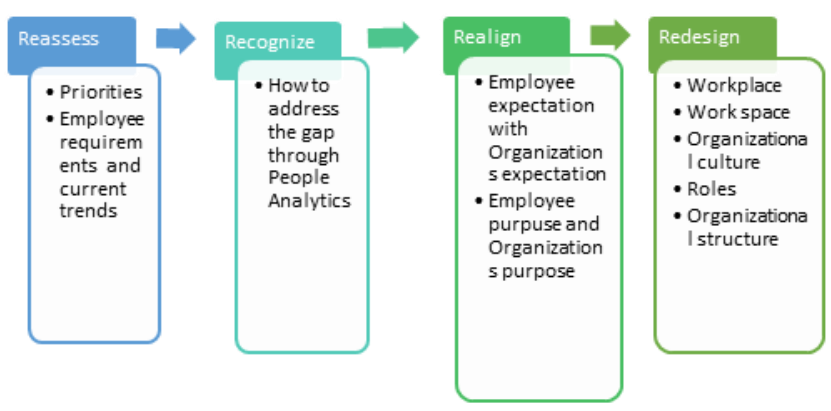

\section{Recognize}

If there is a significant gap, recognizing and analyzing ways to reduce the gap needs to be addressed. Deploying People analytics is key here as it will generate quantitative behavioral data on people and how they work, what they do, how the crisis will affect the way they work, how the behavioral changes can affect business performance.

\section{Realign}

It is crucial to align the employee's expectations and organizations expectations at the earliest, while also aligning the core values and purpose of the organization with the employees.

\section{Redesign}

This is a strategic step and a difficult one. In keeping up with the new normal, organizations need to redesign their workplace, workspaces, organizational culture, roles (especially leadership roles) and organizational structure.

\section{CONCLUSION}

1. With my data analysis and findings, we see that the new Work from Home model which is being employed can be made effective for both employees and organizations keeping in mind certain factors which can build and improve employee experience which is the key to ensuring employees are motivated and productive.

2. How an employee is treated in the crisis is extremely important as it will be remembered by employees and it is an indicator of the relationship between organization and its employees. Organizations which treat its employees the right way surely lead through crises like this one and any more such crises in the future

3. Priorities for people have changed in the crisis, as evidence shows that most employees put their health and family health above anything else. This needs to be aligned with the organizations' priority that they should also put the health of its people first. Having a secure job and a supportive Manager is also on top priority for employees which reinforces that, Organizations need to ensure these basic needs are met for their employees.

4. While upskilling for employees is not an immediate 
priority, it is still seen as an important factor for employees to manage careers. They see the need to be abreast of latest trends in the digital transformation that has been accelerated further by the Covid-19 crisis. Organizations must put this on their immediate agendas to ensure they emerge as thriving through the crisis.

5. Employees motivation and productivity is not a function of the workplace, rather irrespective of the workplace, it is a result of the kind of meaningful work that employees get that matters.

6. One of the other important factors missing in a Work from Home set up is the social interactions, co-ordination and collaboration with colleagues, which impacts the overall team productivity.

7. When it comes to adapting to the new normal, organizations need to also keep in mind that 'one-size-fits-all' approach made not necessarily work for them and they should incorporate tailor made models and customized policies for its employees.

8. With that being established, the front-line managers who are the immediate leaders of the employees can help analyze these factors and what works best for their employees and steer the organizations and employees to thrive in the post Covid-19 era. It is the leaders that must shape the new normal, rather than let it emerge.

For an organization to effectively manage its employees, they must first see the Covid-19 crisis as an opportunity to reassess, recognize, realign and redesign. Covid-19 has levelled the playing field for organizations and given them the perfect start over to leap to a new now and evolve from the old ways.

\section{$\mathrm{X}$. ACKNOWLEDGMENTS}

I would like to thank my family for always being so supportive in all my endeavors and teaching me to be driven, focused and self-motivated.

\section{REFERENCES}

1. Ware J., and Grantham C. (2003). The future of work: Changing patterns of workforce management and their impact on the workplace in Journal of Facilities Management 2(2), (pp.142-159)

2. Celik A., Akgemci T., Akyazi T. (2016). A Comparison between the Styles of Transformational Leaders and Authentic Leaders in Crisis Management in International Journal of Academic Research in Business and Social Sciences, Vol.6, (pp. 183-195).

3. Nakrošiene A., Buciuniene I., Goštautaitè B. (2019). Working from home: characteristics and outcomes of telework in International Journal of Manpower, 10.1108/IJM-07-2017-0172.

4. Strack R., Caye J-M., Thurner R., Haen P. (2009). Creating People Advantage in Times of Crisis. https://www.bcg.com/documents/file15224.pdf
5. Sermenis D.,O'Brien's W. (2019). How various leadership styles apply to corporate Crisis. https://continuityinsights.com/how-various-leadershipstyles-apply-to-corporate-crisis-management/

6. Mazanek L. (2015). Leadership during crisis. https://pdfs.semanticscholar.org/b55a/1103d4d0027c69b7 7021912829a2b440dc23.pdf

7. Eisenberg R. (2020). Is working from home the future of work?

https://www.forbes.com/sites/nextavenue/2020/04/10/isworking-from-home-the-future-of-work/\#7323052646b1

8. Neilson N., D'auria G., Zolley S. (2020). Tuning in Turning outward: Cultivating compassionate leaders in a crisis. https://www.mckinsey.com/businessfunctions/organization/our-insights/tuning-in-turningoutward-cultivating-compassionate-leadership-in-a-crisis

9. Panetta C. (2020) Manage employee stress with flexibility and transparency.

https://www.gartner.com/smarterwithgartner/manageemployee-stress-with-flexibility-and-transparency/

10. Berman M., Thurkow T. (2020). Covid-19 creates a moment of truth for corporate culture. https://www.bain.com/insights/covid-19-creates-amoment-of-truth-for-corporate-culture/

11. Strack R., Bailey A. ,Lovich D., Baier J., Messenböck R., Ruan F., Dyrchs S. ,Kotsis A.(2020). Seven people priorities in response to Covid. https://www.bcg.com/publications/2020/seven-peoplepriorities-in-reponse-to-covid.aspx

12. Sneader K., Singhal S. (2020) Beyond Coronavirus: The path to next normal https://www.mckinsey.com/industries/healthcare-systemsand-services/our-insights/beyond-coronavirus-the-path-tothe-next-normal

13. Redefining the role of the leader in the reskilling era. (2019). https://www.mckinsey.com/businessfunctions/organization/our-insights/redefining-the-role-ofthe-leader-in-the-reskilling-era

14. Wilder J. (2020) How to be a leader not a manager in times of crisis. https://medium.com/swlh/how-to-be-aleader-not-a-manager-in-times-of-crisis-12f33f5817ac

15. Brassey J., Kryut M. How to demonstrate calm and optimism in a crisis. https://www.mckinsey.com/businessfunctions/organization/our-insights/how-to-demonstratecalm-and-optimism-in-a-crisis

16. Celik A., Akgemci T., Akyazi T. (2016). A Comparison between the Styles of Transformational Leaders and Authentic Leaders in Crisis Management. International Journal of Academic Research in Business and Social Sciences, Vol.6, (pp. 183-195).

17. Taplett F., Garcia-Alonso J., Krentz M., Poulsen M.(2020). Frontline Leaders make break progress diversity. https://www.bcg.com/publications/2020/frontline-leadersmake-break-progress-diversity.aspx 
18. Gratton L., (2020) How to help employees work from home with kids. https://sloanreview.mit.edu/article/howto-help-employees-work-from-home-with-kids/

19. 17.Wiles J. (2020). 7 early return to workplace lessons from

Asia.

https://www.gartner.com/smarterwithgartner/7-earlyreturn-to-workplace-lessons-from-asia/

20. Allen J.,Macomber J. (2020). What makes an office building healthy. https://hbr.org/2020/04/what-makes-anoffice-building-healthy

21. How to workforce of the future.(2020) https://www.bcg.com/featured-insights/howto/workforce-of-the-future.aspx

22. Mckinsey Survey (2020) Beyond hiring: How companies are reskilling to address talent gaps. https://www.mckinsey.com/businessfunctions/organization/our-insights/beyond-hiring-howcompanies-are-reskilling-to-address-talent-gaps

23. McGregor L., Doshi N. (2020). How to keep your team motivated remotely.https://hbr.org/2020/04/how-to-keepyour-team-motivated-remotely

24. Purpose shifting from why to how(2020). https://www.mckinsey.com/businessfunctions/organization/our-insights/purpose-shiftingfrom-why-to-how

25. Krentz M., Vaughn E., Ruiz-Cabrero J., Jaafar M. , Teo C.(2020). Diversity Dividend in South East Asia. https://www.bcg.com/publications/2020/diversitydividend-in-southeast-asia.aspx

26. Practical workforce strategies that put your people first.(2020)

https://www2.deloitte.com/global/en/pages/aboutdeloitte/articles/practical-workforce-strategies-that-putyour-people-first.html 